\title{
Causes of Acute Peritonitis and Its Complication
}

Danesh Kumar ${ }^{1}$, Ishan Garg ${ }^{2}$, Atif Hussain Sarwar ${ }^{3}$, Love Kumar ${ }^{1}$, Vikash Kumar ${ }^{4}$, Sonam Ramrakhia ${ }^{5,} 6$ , Sidra Naz ${ }^{7}$, Amna Jamil ${ }^{8}$, Zoya Qamar Iqbal ${ }^{4}$, Besham Kumar ${ }^{9}$

1. Internal Medicine, Liaquat University of Medical and Health Sciences, Jamshoro, PAK 2. Clinical Medicine, Ross University School of Medicine, Bridgetown, BRB 3. Internal Medicine, Ghulam Muhammad Mahar Medical College, Sukkur, PAK 4. Internal Medicine, Jinnah Sindh Medical University, Karachi, PAK 5. Medicine, Liaquat University of Medical and Health Sciences, Jamshoro, PAK 6. Medicine, Mustafai Trust Central Hospital, Sukkur, PAK 7. Internal Medicine, University of Health Sciences, Lahore, PAK 8. Obstetrics and Gynecology, Jinnah Postgraduate Medical Centre, Karachi, PAK 9. Internal Medicine, Jinnah Postgraduate Medical Centre, Karachi, PAK

Corresponding author: Amna Jamil, amnajamil.aj10@yahoo.com

\section{Abstract \\ Introduction}

Peritonitis is a significant cause of morbidity and mortality in surgical settings. Coexisting premorbid illness and postoperative complications were found to be associated with death. This study aimed to analyze various etiologies that cause peritonitis and shed light on the factors responsible for unsatisfactory results.

\section{Method}

This longitudinal study included 309 patients above 12 years of age, of either gender, with confirmed diagnosis of peritonitis. Exploratory laparotomy was done to identify the cause of peritonitis. Patients were monitored postoperatively till their discharge or death for the development of complications.

\section{Results}

Our results showed that the most common cause of acute peritonitis was duodenal perforation (26.2\%), followed by typhoid ileal perforation (24.2\%) and ruptured appendix (16.8\%). At least one complication was observed in $31 \%$ of the participants. The most common complication was dehydration (18.8\%), followed by septicemia (11.3\%) and paralytic ileus (6.4\%). Ten (3.2\%) patients died in the hospital.

\section{Conclusions}

Acute peritonitis is a serious surgical emergency caused by a number of diseases. Early surgical treatment along with antibiotics, followed by aggressive resuscitation can yield improved outcomes in patients with peritonitis.

Review began 05/16/2021 Review ended 05/23/2021 Published 05/28/2021

\section{() Copyright 2021}

Kumar et al. This is an open access article distributed under the terms of the Creative Commons Attribution License CC-BY 4.0., which permits unrestricted use, distribution, and reproduction in any medium, provided the original author and source are credited.
Categories: Gastroenterology

Keywords: peritonitis, etiology, complications, typhoid ileal perforation, ruptured appendix

\section{Introduction}

Peritonitis, an inflammation of the peritoneum, is a life-threatening acute surgical emergency. It presents with severe abdominal pain and is a significant cause of morbidity and mortality ranging from $10 \%-60 \%$ in surgical settings [1]. Existing literature shows that etiologies of peritonitis vary by geographic locations and local environmental factors with genetic predisposition. Appendicitis and typhoid ileal perforation are the common causes of peritonitis with an estimated prevalence of about $43.1 \%$ and $35.1 \%$, respectively [2-3]. Other causes of peritonitis include gastroduodenal perforations, intestinal volvulus, ruptured abscesses, traumatic bowel perforation, perforated peptic ulcers, primary/idiopathic peritonitis, tubo-ovarian abscesses, and amoebic colonic perforations. Knowledge of several distinct causes and presentation of peritonitis in a particular setting will lead to improved local care and better overall understanding of the disease process, as cause is directly related to prognosis [2-3].

Aggressive fluid resuscitation and early surgical intervention are the mainstay of therapy of peritonitis. Enterocutaneous fistulas, surgical site infection, sepsis, and multiorgan failure are the commonest complications seen in surgical settings. Others include abdominal compartment syndrome, wound dehiscence, and respiratory insufficiency. Complications are influenced by advanced age and comorbidities. Coexisting premorbid illness and postoperative complications were found to be associated with death $[4,5]$. Despite the rapid advancement in surgical techniques, modified antimicrobial therapies, and intensive care support, the management of peritonitis continues to be more demanding, challenging, and complex than ever [4].

Severely ill patients usually present in the late stage of the disease. Consequently, there is less time for 


\section{Cureus}

diagnostic approaches and proper decision-making for a strong treatment method. Lack of awareness, late presentation, and its correlation with morbidity and mortality demonstrate that there is room for betterment in medical treatment by a thorough examination of the etiologies, presentation, and results. Prior studies primarily focused on single etiologies; therefore, they have not focused on interconnected etiologies. The present study aimed to analyze various etiologies of peritonitis and shed light on the factors responsible for unsatisfactory results.

\section{Materials And Methods}

This longitudinal study was conducted in the emergency unit of a tertiary care hospital in Pakistan from January 2019 to March 2021. Patients with a confirmed diagnosis of peritonitis above 12 years of age and of either gender, which included 309 patients, were included in the study. Patient were enrolled via consecutive convenient non-probability technique. Their informed consent was taken. Ethical review board approval was taken before start of patient enrollment. Diagnosis of peritonitis was made based on clinical and radiological findings. Clinical findings included abdominal pain, vomiting, constipation, generalized abdominal tenderness, and absent bowel sounds. Peritonitis was indicated by X-ray showed air under the diaphragm.

Exploratory laparotomy was done to identify the cause of peritonitis. Operative findings like duodenal perforation, ileal perforation, ileal stricture with perforation, and ruptured appendix were noted in a selfstructured questionnaire. Surgical intervention was done when required and the cause of perforation was treated. Patients were monitored postoperatively for the development of complications. Complications such as organ failure, septicemia, peritoneal abscess, paralytic ileus, burst abdomen, and surgical site infection were recorded. Complications due to ileostomy or any other surgical intervention were not taken into consideration in this study. Statistical Package of Social Sciences (SPSS) for Windows, version 22.0 (IBM Corp., Armonk, NY) was used to analyze data. Frequencies and percentages were calculated for categorical variables.

\section{Results}

Acute peritonitis was more common in males (65.0\%) and in the age group from 21 to 40 years (Table 1).

\begin{tabular}{|l|l|}
\hline Demographics & Frequency (percentage) \\
\hline Gender & \\
Male & $201(65.0 \%)$ \\
Female & $108(35.0 \%)$ \\
Age group in years & \\
$12-20$ & $77(24.9 \%)$ \\
$21-40$ & $97(31.3 \%)$ \\
$41-60$ & $79(25.5 \%)$ \\
$60+$ & $56(18.1 \%)$ \\
\hline
\end{tabular}

TABLE 1: Demographics of the participants enrolled.

The most common cause of acute peritonitis was duodenal perforation (26.2\%), followed by typhoid ileal perforation (24.2\%) and ruptured appendix (16.8\%) (Table 2). 


\section{Cureus}

\section{Causes}

Duodenal perforation

Typhoid ileal perforation

Ruptured appendix

Tuberculosis perforation

Tumor perforation

Liver cirrhosis

Gangrenous gut

Acute pancreatitis

Acute diverticulitis

Pelvic inflammatory disease
Frequency (percentage)

$81(26.2 \%)$

$75(24.2 \%)$

$52(16.8 \%)$

$31(10.0 \%)$

$21(6.7 \%)$

$19(6.1 \%)$

$15(4.8 \%)$

$06(1.9) \%$

05 (1.6\%)

$04(1.2 \%)$

TABLE 2: Causes of acute peritonitis.

At least one complication was observed in 97 (31.3\%) participants. The most common complication was dehydration (18.8\%), followed by septicemia (11.3\%), and paralytic ileus (6.4\%). Ten (3.2\%) patients died in the hospital (Table 3).

\begin{tabular}{|l|l|}
\hline Complications & Frequency \\
\hline No complications & $212(68.6 \%)$ \\
Septicemia \& organ failure & $57(18.4 \%)$ \\
Paralytic ileus & $35(11.3 \%)$ \\
Burst abdomen & $20(6.4 \%)$ \\
Surgical site infection & $19(6.14 \%)$ \\
Enterocutaneous fistulas & $15(4.8 \%)$ \\
Hepatorenal syndrome & $11(3.5 \%)$ \\
Hepatic encephalopathy & $01(0.3 \%)$ \\
\hline
\end{tabular}

\section{TABLE 3: Complications of acute peritonitis.}

\section{Discussion}

The present study demonstrated peritonitis was significantly more prevalent in males, with a peak age group of 21-40 years. Among the factors causing peritonitis, duodenal perforation was the most common, followed by typhoid ileal perforation and ruptured appendix. Postoperative morbidity rate was $31.3 \%$ with dehydration being the most common complication, followed by septicemia and paralytic ileus. The mortality rate was $10 \%$.

The findings of the present study are also supported by a study conducted by Choua et al. [6], who found that males were at a higher risk of developing peritonitis, and the average age of the participants was 25.8 years. The most common cause according to their study was visceral perforation, followed by diffuse appendiceal peritonitis. Participants in the present study also had duodenal perforations and affected appendix as the primary cause [6]. However, the morbidity and mortality rates in their study were lower than those of the present study. Another study carried out by Hagos et al. also showed similar results [7]. Males were seen to develop peritonitis more frequently. Acute appendicitis and perforated peptic ulcer disease were among the common causes; problems with appendix and visceral perforations were also observed in the present study. 
The morbidity rate was $30.8 \%$ in their study, with wound infections and sepsis being common complications, which was also observed in the present study. However, the mortality rate in the present study was $10 \%$. Mortality rates in some other studies were $11.8 \%$ [8] and $12.63 \%$ [9]. The possible explanation for this variation in mortality rate is early diagnosis and presentation accompanied with effective surgical treatment.

Helicobacter pylori is the main causative agent of acute peritonitis secondary to duodenal perforation [10]. It is more common in developing countries where people do not have access to mineral water. However, boiling tap water would prevent peritonitis, and physicians are advised to diagnose and treat $H$. pylori infections with triple therapy including proton pump inhibitors (PPIs) at an early stage to avoid secondary complications [11]. Another leading cause is typhoid ileal perforation; typhoid fever is progressively being eradicated in most parts of the world but it is still endemic in India. Typhoid frequently leads to intestinal hemorrhage causing increased mortality and morbidity [12]. Moreover, the third leading cause was ruptured appendix as shown in other studies by Schietroma et al. [13] and Lin et al. [14]. However, most of these causes are due to unsanitary conditions and the use of contaminated water. The adaptation of a healthy lifestyle accompanied by early diagnosis and aggressive resuscitation, in addition to prompt surgical intervention can help avoid complications of acute peritonitis [15].

\section{Conclusions}

Acute peritonitis, a serious surgical emergency, is caused by a number of diseases. According to the present study, H. pylori infections leading to duodenal perforation, typhoid ileal perforation, and ruptured appendix are the most common causes. These can be avoided by leading a hygienic lifestyle. In the case of $H$. pylori infection, PPI maintenance therapy can help avoid reinfection. Moreover, early surgical treatment along with antibiotics followed by aggressive resuscitation can yield improved outcomes for peritonitis.

\section{Additional Information \\ Disclosures}

Human subjects: Consent was obtained or waived by all participants in this study. Jinnah Sindh Medical University issued approval JSMU/IRB/2019/32. Animal subjects: All authors have confirmed that this study did not involve animal subjects or tissue. Conflicts of interest: In compliance with the ICMJE uniform disclosure form, all authors declare the following: Payment/services info: All authors have declared that no financial support was received from any organization for the submitted work. Financial relationships: All authors have declared that they have no financial relationships at present or within the previous three years with any organizations that might have an interest in the submitted work. Other relationships: All authors have declared that there are no other relationships or activities that could appear to have influenced the submitted work.

\section{References}

1. Skipworth RJ, Fearon KC: Acute abdomen: peritonitis. Surgery. 2008, 26:98-101. 10.1016/j.mpsur.2008.01.004

2. Ohene-Yeboah M: Causes of acute peritonitis in 1188 consecutive adult patients in Ghana . Trop Doct. 2005, 35:84-5. 10.1258/0049475054036788

3. Samuel JC, Qureshi JS, Mulima G, Shores CG, Cairns BA, Charles AG: An Observational Study of the Etiology, clinical presentation and outcomes associated with peritonitis in Lilongwe, Malawi. World J Emerg Surg. 2011, 6:37. 10.1186/1749-7922-6-37

4. Mabewa A, Seni J, Chalya PL, Mshana SE, Gilyoma JM: Etiology, treatment outcome and prognostic factors among patients with secondary peritonitis at Bugando Medical Centre, Mwanza, Tanzania. World J Emerg Surg. 2015, 10:47. 10.1186/s13017-015-0042-5

5. Malik M, Iqbal M, Magsi AM, Parveen S, Khan MI, Shamim M, Malik S: Causes of acute peritonitis and its outcome in tertiary medical centre. J Liaquat Uni Med Health Sci. 2019, 18:193-6. 10.22442/jlumhs.191830626

6. Choua O, Ali MM, Kaboro M, Moussa KM, Anour M: Etiological, clinical, and therapeutic aspects of acute generalized peritonitis in N'Djamena, Chad. Med Sante Trop. 2017, 27:270-3. 10.1684/mst.2017.0696

7. Hagos M: Acute abdomen in adults: a two year experience in Mekelle, Ethiopia . Ethiop Med J. 2015, 53:1924.

8. Malhotra MK, Singal R, Chowdhary K, Sharma RG, Sharma S, Dhankhar A: Spectrum of perforation peritonitis in a rural medical college. Bangladesh J Med Sci. 2016, 15:70-3. 10.3329/bjms.v15i1.20857

9. Garg RK, Gupta R, Kailasia Y, Chhari AS, Jain M, Dubey C: Spectrum of nontraumatic perforation peritonitis: a prospective study of 277 cases with special reference to morbidity and mortality. Int Surg J. 2016, 3:1223-8. 10.18203/2349-2902.isj20161435

10. Magsi AM, Iqbal M, Malik M, Parveen S: Silent peptic ulcer disease perforation. J Surg Pak. 2017, 22:61-4.

11. Lai KC, Lam SK, Chu KM, et al.: Lansoprazole for the prevention of recurrences of ulcer complications from long-term low-dose aspirin use. N Engl J Med. 2002, 346:2033-8. 10.1056/NEJMoa012877

12. Saxe JM, Cropsey R: Is operative management effective in treatment of perforated typhoid? . Am J Surg. 2005, 189:342-4. 10.1016/j.amjsurg.2004.11.032

13. Schietroma M, Piccione F, Carlei F, Clementi M, Bianchi Z, de Vita F, Amicucci G: Peritonitis from perforated appendicitis: stress response after laparoscopic or open treatment. Am Surg. 2012, 78:582-90.

14. Lin HF, Lai HS, Lai IR: Laparoscopic treatment of perforated appendicitis. World J Gastroenterol. 2014, 


\section{Cureus}

20:14338-47. 10.3748/wig.v20.i39.14338

15. Bhandari TR, Poudel R, Chandra K: Effect of early surgery on outcome in perforation peritonitis . J Univers Coll Med Sci. 2017, 5:12-6. 10.3126/jucms.v5i1.19048 